\title{
LA BELLA CARNICERA Y EL JOVEN COPRÓFILO. CIENCIA, MÉTODO Y ÉTICA DEL PSICOANÁLISIS
}

The beautiful butcher and the young afflicted with coprophilia. Science, method and ethics of psychoanalysis.

Héctor Ponce Bogino*

\begin{abstract}
Resumen
Se reflexionará acerca de la epistemología y metodología de Freud, además sobre cómo valorar éticamente los hallazgos recientes de la correspondencia privada de Freud en la que se niega la recuperación de algunos pacientes que Freud sostuvo haber tratado.

El objetivo es una evaluación personal; las fuentes son bibliográficas; y las conclusiones son: 1) En epistemología el psicoanálisis se ubica dentro de las ciencias humanas y Freud creó una valiosa teoría de la mente como portadora de varias voluntades que permite nuevas formas de retrospección. 2) En metodología, el psicoanálisis se enriquece si, en lugar de apelar a las "leyes del inconsciente", se inspira en la hermenéutica. 3) En ética, Freud no fue veraz al presentar como procesos culminados a varios pacientes que terapéuticamente no mejoraron, y la comunidad psicoanalítica no se ha pronunciado debidamente.
\end{abstract}

Palabras clave: Psicoanálisis, epistemología, metodología, terapia y epistolario de Freud.

\begin{abstract}
We are going to reflect on the epistemology and methodology of Freud, furthermore about how evaluate ethically the recent findings of the private correspondence of Freud in which the recovery of some patients is denied who have been treated by Freud.

The objective is a personal evaluation; the sources are bibliographical; and the conclusions are: 1) In Epistemology, the psychoanalysis is located in human sciences and Freud created a valuable theory of mind as a carrier of many wills that allows new forms of retrospect. 2) In methodology, the psychoanalysis is enriched if, instead of appeal to the "laws of the unconscious", is inspired in hermeneutics. 3) In Ethics, Freud was not truthful, when he presented as culminated process, many patients who therapeutically do not improve, and the psychoanalytical community has not acted properly.
\end{abstract}

Keywords: Psychoanalysis, epistemology, methodology, therapy and Freud's collection of letters.

\footnotetext{
* Filósofo. Docente Universidad Ruiz de Montoya y Universidad Peruana de Ciencias Aplicadas. heaponce@yahoo.es
} 


\section{LA MISIÓN DE FREUD}

Freud es un ensayista difícil de catalogar, cuando sus discípulos le rinden adhesión y culto, la figura de Freud se transforma en la de un patriarca totémico, mientras que cuando son los adversarios quienes le dedican críticas letales, la biografía del padre del psicoanálisis resulta atractiva. Así sucede al terminar de leer las más de seiscientas páginas de El libro negro del psicoanálisis. Vivir, pensar y estar sin Freud (Borch-Jacobsen, Mikkerl; Jean Cottraux; Didier Pleux y Jacques Van Rillaer. 2005), texto que recoge sesenta misiles en forma de artículos contra los psicoanalistas y en especial contra Freud -a quien se le atribuyen todos los defectos y vicios de los que es capaz la especie humana, tildándosele de errado e iluso, y, más grave, de falsificador-, por lo que, aún electrizado, el lector cierra el libro pensando que al menos Freud no fue tachado de mal escritor, aunque señalan que sus textos son ambiguos, algo que desde otra perspectiva es un mérito. La prosa persuasiva y bicéfala de Freud desarrolla con ingenio una tesis y su contraria, como cuando planteaba que la religión, como delirio colectivo, intimida e infantiliza a la inteligencia (El malestar en la cultura.1930, p. 3022), pero también veía en ella el mérito de abordar temas esenciales para la humanidad. Como escritor dialéctico, Freud tenía una versatilidad que, algunas veces, lo llevaba a describir al melancólico con ironía perversa: "cuando en su autocrítica el melancólico se describe como un hombre pequeño, egoísta, insincero y carente de ideas propias, preocupado siempre en ocultar sus debilidades, nos preguntamos por qué ha tenido que enfermar para descubrir tales verdades" (Duelo y melancolía. 1917, p. 2093). Para Freud las necesidades religiosas son consecuencias del desamparo infantil y de la nostalgia por el padre, más la angustia ante la omnipotencia del destino; y sin embargo, otras veces, su estilo dejaba la diplomacia y encaraba a los lectores: podría moderar su opinión pero, a diferencia de la mayoría, él no cedería a la pusilanimidad, ni alimentaría vanas esperanzas, pues no escribía para la clientela.

Ese estilo, sincero y mordaz, sin complacencia, atraía a los intelectuales. Las personas podían independizarse de traumas, fobias, depresiones y otras formas de neurosis, siempre uno se atreviera a conocer las causas o las elecciones que en el pasado han hecho lo que somos y así reactivaba los ideales filosóficos de la Ilustración, el "piensa por ti mismo" de Kant, desactivar represiones de la misma manera en que Marx quiso eliminar las ideología y la idea de que el autoconocimiento nos liberaba. Pero, a la vez, el método psicoanalítico erosionaba las bases del Racionalismo al sostener que varias de nuestras intenciones no provienen de la conciencia y la razón, sino de estratos mucho más profundos y abisales. Se comprende -como lo pensó Erich Fromm (The Crisis of Psychoanalysis. 1970)- que el pensamiento de Freud influyera al siglo XX al permitir la deseada síntesis de dos movimientos antagónicos: la Ilustración y el Romanticismo. Freud conciliaba tanto el escepticismo de Locke y Hume como la pasión de Byron y Goethe, tanto la razón de Hobbes y Kant como los abismos de Poe y Blake, y sintetizaba tanto las descripciones minuciosas de Dickens y Víctor Hugo como los conceptos iconoclastas de Marx y Nietzsche.

Con expectativas tan altas se entiende la ilusión de integrar la transparencia de la Ilustración y las tinieblas del Romanticismo y que no se prestara oídos a los críticos que se ocupaban, después de todo, de circunstancias menores en comparación con la gran meta liberadora del diván. Los críticos cuestionaban al psicoanálisis como ciencia (Karl Popper. Conjectures and Refutations.1974 [1961]) y el método con que recolectaban datos (Grünbaum. The foundations of psychoanalysis: Aphilosophicalcategories. 1984), pero si esos críticos no fueron escuchados debió de ser por la misma razón que tienen los feligreses cuando se les muestra las arbitrariedades que existen en los dogmas que abrazan. Tanto el creyente como el seguidor del psicoanálisis, en la versión más ortodoxa, podrán decir que las contradicciones son sólo detalles y discusiones insignificantes que nunca harán trastabillar a la vida en movimiento de las esperanzas y alivios ofrecidos ya sea en la liturgia, ya sea en el diván. Así las cosas, entre los pros y contras de mantener al psicoanálisis como teoría de la mente, los contras eran sólo de interés para los académicos y, en cambio, los pros eran altísimos al alentar que cada persona viviera una transformación en su existencia ${ }^{1}$.

1. Y hasta el día de hoy no deja de ser interesante pensar la sexualidad como la infraestructura desde la que se levanta nuestro edificio mental e interpretar un problema bajo la expresión -creada por Breuer- de secrets d'alcôve o como menos elegantemente subrayó Charcot 
Si es cierto que la existencia es transformada por la experiencia psicoanalítica y que la sexualidad es una de las llaves maestras que abren la intimidad de la mente, el destino que tendrán las críticas esgrimidas en El libro negro será el olvido, como ocurrió con críticos como Hans Eysenck (Decadencia y caída del imperio freudiano.1985), aunque esta vez no queda ningún flanco ileso del psicoanálisis. Antes la teoría freudiana fue examinada en su aspecto epistemológico y metodológico, ahora es expurgada incluso en lo ético.

\section{LA BELLA CARNICERA: EL PSICO-ANÁLISIS COMO CIENCIA Y COMO ARQUEOLOGÍA DE LA MENTE}

A inicios del siglo XX Freud publicó La interpretación de los sueños y ahí sostuvo, además de la tripartición de la mente en consciente, preconsciente e inconsciente" (Elizabeth Roudinesco y Michel Plon. Diccionario de psicoanálisis. 1998. p. 543), que los sueños, vistos bajo el lente de aumento del psicoanálisis, poseen un sentido oculto: en ellos realizamos un deseo prohibido. Pero, ¿qué pensar de las pesadillas?, le preguntó una paciente, años después bautizada por Jaques Lacan como "La bella carnicera" por ser esposa de un carnicero y carnicera de su propio deseo (Jaques Lacan. Seminario 5. Las formaciones del inconsciente.). Ella le expuso a Freud:

Dice usted que todo sueño es un deseo cumplido -me expone una ingeniosa paciente-. Pues bien: le voy a referir uno que es todo lo contrario. En él se me niega precisamente un deseo. [...] Quiero dar una cena, pero no dispongo sino de un poco de salmón ahumando; pienso en salir para comprar lo necesario, pero recuerdo que es domingo y que las tiendas están cerradas. Intento luego telefonear a algunos proveedores, y resulta que el teléfono no funciona. De este modo, tengo que renunciar al deseo de dar una cena. (La interpretación de los sueños. 1900, p. 333).
Detrás del diván, manipulando algunas de las estatuillas que poblaban sus estantes de libros, Freud le explicó que explicó que esos sueños le proporcionaban un deseo insatisfecho. En los sueños se deforman los deseos como en los jeroglíficos que disfrazan y camuflan un mensaje ${ }^{2}$ ¿ ¿Por qué una persona tendría que sufrir tales emboscadas del inconsciente? En cada sujeto existiría una tensión entre realizar un deseo y procrastinar ese deseo, y, como los gestos de cortesía y los buenos modales, el sueño encubre los deseos agresivos.

Fue Karl Popper quien, en 1961, cuestionó las explicaciones que sólo ofrecen confirmaciones y nunca posibles contraejemplos. En Conjeturas y refutaciones, cuenta que en 1919, aún joven, quedó impresionado al encontrarse con el psicoanalista Alfred Adler. En presencia de Popper, un niño había sido evaluado por Adler, pero sin haber sido observado jamás; Popper preguntó cómo podía estar seguro del diagnóstico, y Adler respondió: "por mi experiencia de mil casos" y Popper replicó: "y con este nuevo caso su experiencia se basa en mil y un casos". El problema epistemológico del psicoanálisis (Alan Chalmers. ¿Qué es esa cosa llamada ciencia? 2005) es que sólo registra las predicciones que confirman sus ideas y olvida las predicciones desacertadas; además, sus predicciones abarcan tantas posibilidades que resulta imposible errar (como afirmar que mañana lloverá o no lloverá). El psicoanálisis confirma sus ideas en múltiples eventos, desde sueños y guerras hasta chistes y lapsus, pero dichas confirmaciones carecen de valor, pues no presenta contra-ejemplos que refutarían sus explicaciones (como sí lo hizo la teoría de Einstein). Es sospechoso, además, que una teoría se blinde constantemente, con parches y recosidos, con explicaciones ad hoc, y sea inmune a la crítica. En una oportunidad, Freud planteó la regla de que "la conducta sexual de una persona constituye el prototipo de todas sus demás reacciones" (La moral sexual y la nerviosidad moderna, 1908, p. 1258); pero, si es así, entonces cómo un célibe como Kant pudo

cuando, al referir que los problemas nerviosos de una joven eran causados por la torpeza sexual del esposo, dijo que, en casos semejantes, se trataba siempre del asunto genital: "Mais, dans des cas pareils c'est toujours la chose génitela, toujours... toujours... toujours".

2. "La sintomatología histérica puede compararse a una escritura jeroglífica que hubiéramos llegado a comprender después del descubrimiento del algunos documentos bilingües. En este alfabeto, los vómitos significan repugnancia". Sigmund Freud. "Estudios sobre la histeria", en: Obras completas. Traducción de Luis López-Ballesteros y de Torres. Madrid: Editorial Biblioteca Nueva, 1948, VOL. I, p. 75. 
ser un fecundo creador intelectual (Michel Onfray. El vientre de los filósofos. 1996, p. 59). La respuesta psicoanalítica hará una excepción de la anterior regla y mostrará una nueva idea: Kant sí era sexómano, pero sublimado.

Frente a la perspectiva de Popper, algunos psicoanalistas esgrimen una defensa interesante condensada por Aristóteles: "Es propio del hombre instruido buscar exactitud en cada materia en que la admite la naturaleza del asunto; evidentemente, tan absurdo sería aceptar que un matemático empleara la persuasión como exigir de un retórico demostraciones" (Ética Nicomáquea. I 3, 1094b 23-27). Y, sin embargo, el problema radica en que Freud aspiraba a ser científico, un fisiólogo ocupado de la mecánica de las descargas y el equilibrio de los quantum pulsionales, aunque es cierto que en otras ocasiones comparaba la interpretación psicoanalítica con el desciframiento de un arqueólogo.

En la actualidad, tal como describe Joan Coderch (La interpretación en psicoanálisis, 1995), existen dos vertientes psicoanalíticas al interpretar: la lógicodeductiva y la intuitiva-empática. La primera pretende hacer ciencia natural sobre la mente del paciente, el analista tantea una hipótesis sobre la mente del paciente y se apoya en la metapsicología freudiana (en las leyes del proceso primario y secundario del inconsciente). La vertiente intuitiva-empática (hermenéutica y relacional), en cambio, subraya el rol del diálogo terapéutico que busca interpretar los jeroglíficos que el propio paciente plantea. Frente a estos dos modos de comprender al psicoanálisis, Freud no tenía la claridad de hoy. Cuando se sostiene que el objetivo psicoanalítico es lograr que el paciente tome conciencia de lo reprimido en el pasado y, seguidamente, se afirma que el origen de los síntomas está en la hidráulica de las pulsiones, se recae en la confusión de Freud. Un modo interesante de enfrentar las críticas de Popper es ubicarse en el ámbito de las ciencias humanas, aunque, por cierto, psicoanalistas como Joan Coderch mantienen el ideal de ser científicos pero a la manera renovada del filósofo de la ciencia Thomas Kuhn en The Structure of Scientific Revolutions de 1962.

Si se cree erradamente que los únicos aportes valiosos a la humanidad son los de Galileo, Newton y Einstein, y no los de Dante, Edmond Rostand y Marcel Proust, entonces se cree erradamente que pertenecer a las ciencias humanas le resta méritos a Freud. En esta línea, la originalidad freudiana no se debe ni al intento de construir una mecánica de pulsión-conflicto-defensa (David Hume pretendió una labor similar) ni al intento de generar un insight en el paciente (Sócrates también lo hizo). Tampoco la historia le hubiese reservado ningún espacio a Freud entre los creadores por decir que lo inconsciente era un territorio maldito: veinticinco siglos antes las pasiones fueron así descritas por Platón. Hubo filósofos modernos que mencionaron al inconsciente, pero como una fosa en que se lanzan cadáveres olvidados ${ }^{3}$. Lo original en Freud es haber interpretado la mente como si en ella existieran voluntades distintas a la voluntad consciente, y que tales voluntades, desde la trastienda, realizan sus propias elecciones. Serían voluntades inconscientes que, siendo justificadas para un sector de creencias de la mente, aún no están vinculadas entre sí y de las que no tiene noticias nuestra voluntad consciente. Esta perspectiva es celebrada por el filósofo Donald Davidson en "Paradoxes of irrationality" (R. Wollheim y J. Hopkins (comps.), Philosophical Essays on Freud, 1982).

La mente sería el escenario en que cohabitan la voluntad consciente y otras voluntades inconscientes, extrañas y familiares a la vez. A lo mejor estas ideas sean más aceptables si se considera la distinción propuesta por los funcionalistas entre cerebro y mente semejante a la diferencia entre hardware y software: al

3. El psicoanálisis recusa "dos tesis filosóficas opuestas y complementarias: por una parte, el conciencialismo, que excluye al inconsciente de la vida psíquica; por otra parte, el trascendentalismo del Inconsciente (aquí las mayúsculas tiene un sentido) que convierte al inconsciente en entidad metafísica. Este doble efecto revelador ataca, pues, una tesis única: El divorcio del inconsciente y de lo psíquico". PaulLaurent Assoun. "La filosofía y el obstáculo concientalista", en: Freud. La filosofía y los filósofos. Traducción de Alberto Luís Bixio. Buenos Aires: Ediciones Paidós, 1982,p. 39. Assoun continúa: "De manera que la filosofía del inconsciente estaba condenada a naufragar en el Caribdis del irracionalismo místico o en el Escila del psicologismo conciencialista." Op. cit., p. 40 
cerebro le corresponde la estructura neurofisiológica, mientras a la mente le pertenecen distintos contenidos borboteando y en ebullición. Sería entonces en el software en el que la hipótesis de Freud daría luces, compitiendo con muchas otras metáforas sobre la mente, como la de Platón, como la de Nietzsche y como la fina metáfora de Coleridge para quien habían horizontes de la mente que era como "los reinos crepusculares de la conciencia" (Peter Gay. Freud. Una vida de nuestro tiempo. 1990, p. 413) y como la de Wordsworth: "En mi mente hay cavernas a las que el sol/ nunca podría llegar" (William Wordsworth. "Preludio" Libro Primero, I. 562, 2003).

La peculiaridad de la metáfora de Freud concibe a la mente como poblada por un enjambre de voluntades cada una respaldada por un conjunto de razones articuladas y coherentes entre sí. De ser apropiada esta comparación, cada vez que actuamos de manera supuestamente irracional, podríamos averiguar qué razones hubo para realizar dicha acción y, de conseguirlo, iluminaríamos lo irracional con lo racional. Las reflexiones tanto de Davidson como de Rorty (Ensayos sobre Heidegger y otros pensadores contemporáneos. 1993) van en la dirección disolver la dicotomía entre una subjetividad substancial y las patéticas pasiones -heredada desde Platón-, y postulan -siguiendo a Nietzsche y Freud- que nuestra mente ni es monolítica ni transparente: la mente sería un enjambre de yoes -muchos de ellos desconocidosque mantiene cierta línea de acción. Nuestra mente es, de acuerdo a esta concepción, como los músicos de un conjunto que, sin ningún director de orquesta que los dirija, van tocando sus instrumentos a su antojo, y la finalidad de la terapia psicoanalítica es lograr que esos músicos acuerden e interpretar algunas partituras menos caóticamente. Uno de los yoes de la mente puede sentirse vanaglorio al ser observado, mientras que otros yoes pueden avergonzarse por ello, y el ideal de la terapia es comprender los dos deseos antagónicos, ampliar las alternativas y crear perspectivas distintas que toleren la ambiguiedad y se expandan en redescripciones sutiles y matizadas.

Davidson y Rorty aplauden la teoría psicoanalítica por el modelo intersubjetivo de la mente, sin detenerse en los detalles problemáticos de la artillería metapsicológica de Freud. Es irónico que por ser filósofos Freud los interpretara como refinados coprófilos, como lo profetizó en 1913 sobre un joven filósofo sin mayor justificación. Aunque tal vez Freud aterrizaba así a los intelectuales, recordándoles el barro del que proceden y sus hoscos gustos decorados.

Un joven y espiritual filósofo, con actitudes estéticas exquisitas, se apresura a enderezarse la raya del pantalón antes de acostarse para la primera sesión; revela haber sido antaño un coprófilo de extremo refinamiento, como cabía esperarlo (Sobre la iniciación del tratamiento, 1913; citado en Michel Onfray. El crepúsculo de un ídolo. 2011, p. 306).

\section{LA BARONESA: MÉTODO Y TERAPIA PSICOANALÍTICOS}

Adiferencia de la relación tradicional entre médico y paciente, sacerdote y creyente, Freud alentaba a sus pacientes a escarbar detalles en recuerdos agradables, pero también hurgando entre montículos de penosas inmundicias. La técnica de la asociación libre de ideas empezó cuando la baronesa Fanny Moser, paciente de Freud que padecía tics convulsivos y alucinaba con ratas muertas y serpientes que se retorcían, al ser interrumpida por preguntas de Freud, le exigió furiosa que la dejara hablar (Estudios sobre la histeria, 1985). La baronesa narraba una 'novelería familiar', forjaba una 'crónica familiar' de personajes nocivos con momentos de nobleza, personajes distantes y de cierta solidaridad silenciosa, y personajes vegetativos de omisiones imperdonables. En 1900 Freud publicó La interpretación de los sueños creyendo que los sueños, fobias, obsesiones, delirios tienen un sentido (p. 234). $\mathrm{Al}$ escuchar las asociaciones libres, el psicoanalista, abriéndose paso con una guadaña entre la maleza de los contenidos insignificantes, obra como un traductor, mostrando al paciente las posibles piedras y flores relevantes del camino, y juntos emprenden el camino. Se trata de un traductor que confía al propio paciente "el trabajo de interpretación, no atendiendo sino a lo que al propio paciente se le ocurre" (La interpretación de los sueños, 1900, p. 308).

Una persona emprende ese desciframiento en compañía del psicoanalista para evitar autoengañarse. El psicoanalista evitaría el auto-engaño. 
Según Freud, en las pesadillas, las personas deforman sus deseos, pues, incluso en los sueños, los deseos son reprimidos y maquillados, y el contenido real del sueño se disfraza por los mecanismos de la condensación y el desplazamiento sobre los que el paciente no tiene dominio. Pero incluso aparece otro mecanismo que el paciente despierto no controla: la resistencia. Los pacientes, muchas veces, se resisten a aceptar las interpretaciones de sus síntomas y, así, inconscientemente, obstaculizan la terapia. Existe la resistencia de tipo intelectual, en la que el paciente discute la validez epistemológica del psicoanálisis, y de las distintas clases de resistencias, agudamente, Freud indicó que la más problemática es la resistencia complaciente.

El denominado 'buen paciente' -que sueña en abundancia, establece asociaciones sin vacilar, considera brillantes todas las interpretaciones, nunca llega tarde, paga sin retrasarse los honorarios- representan un caso en especial intratable, precisamente porque sus intenciones son muy difíciles de descifrar. (Peter Gay. Freud. Una vida de nuestro tiempo. 1990, p. 342).

Es fácil reconocer la utilidad de las resistencias en los masoquistas, que hallan placer en el dolor, pero Freud observó que el neurótico común encuentra satisfacciones secundarias al convivir con su malestar: continuar la terapia significa sacar debajo de la alfombra el polvillo de los cadáveres y las heridas más dolorosas que un lado del neurótico no quiere. Como buen lector de Shakespeare, entre otros escritores, Freud comprendió que, por lo general, las situaciones pueden evaluarse tanto negativa como positivamente, $\mathrm{y}$ las resistencias eran un estorbo pero también permitían conocer los mecanismos de defensa de la baronesa. Cómo se vinculaba, la intensidad de sus emociones hostiles, cómo iba enamorándose de su psicoanalista y exhibía su erotismo, todo eso le iba mostrando a Freud la personalidad de su paciente: la baronesa le "transfería" un tipo de vínculo intenso. A sus discípulos Freud les recomendaba nunca discutir con el paciente recordando una anécdota. Por convicción piadosa y desesperada de la familia, un agente de seguros, incrédulo y que está en el lecho de muerte, es obligado a soportar los servicios de extrema unción de un sacerdote a puertas cerradas. La familia del agente tiene fe en que el hombre agonizante acepte la luz de la fe. "La conversación dura tanto que los familiares empiezan a esperanzase. Por fin la puerta de la habitación del enfermo se abre. El incrédulo no ha sido convertido, pero el sacerdote sale del lugar con un seguro de vida" (Freud. Puntualizaciones sobre el amor de transferencia. 1914. Citado en Peter Gay Freud. Una vida de nuestro tiempo 1990, p. 345).

No obstante, conocer los mecanismos de la condensación, el desplazamiento, la resistencia y la transferencia, ibastaban para psicoanalizar a la baronesa? Según Freud, estos conocimientos conducían a un "psicoanálisis salvaje" (El psicoanálisis silvestre. 1910, pp. 1571-1574), como el recibido por una mujer a la que un médico le explicó que su ansiedad era causada por falta de satisfacción sexual, sugiriéndole el onanismo. Freud, indignado, desaprobó el consejo del médico, pues no tenía asidero en el psicoanálisis; sin embargo es curioso que hacía unos años el propio Freud, basado en la metapsicología, recomendaba a un caso la masturbación (La moral sexual y la nerviosidad moderna. 1908, pp. 1249-1261). ¿Qué diferencias hay entre "psicoanálisis salvaje" y "psicoanálisis institucionalizado”? ¿El "psicoanálisis institucionalizado sigue procedimientos estandarizados y controlados por otros psicoanalistas? Nuevamente aparece la tensión entre el método científico que busca explicar con leyes universales a los pacientes y el modelo hermenéutico que intenta que la baronesa comprenda su propia idiosincrasia.

En la tensión entre la explicación metodológica de las ciencias naturales y la comprensión de las humanidades, se encuentra la posición de Freud cuando, por un lado, analiza los problemas psíquicos como un sistema de poleas entre pulsiones y defensas, $\mathrm{y}$, de otro lado, cuando comprende la mente de la baronesa atestada de personajes y diálogos caóticos. Un ejemplo de la tensión de ambos modelos está en la asociación libre -actividad que André Green halagó como la invención más demoníaca de Freud-, pues para varios psicoanalistas la asociación libre se rige por supuestas "leyes del inconsciente" mientras que para otros psicoanalistas no existen tales leyes, y cuando la baronesa cayó a Freud le indicó que atendiera a los detalles. Ernest Jones rastreando la genealogía de esta invención demoníaca encontró similitudes con el libre fluir de los escritores. 
Cuando Freud depositó su confianza en el valor de las asociaciones libres dijo que estaba 'siguiendo una oscura intuición'. Poseemos ahora una clave reveladora del origen de esta interesante intuición. Cierto autor, de nombre Ludwig Börne, había escrito en 1823 un ensayo que llevaba el atractivo título de 'El arte de convertirse en escritor original en tres días'. Terminaba con las siguientes palabras: 'He aquí la receta [...]. Tome hojas de papel y durante tres días sucesivos escriba, sin falsedad ni hipocresía de ninguna clase, todo lo que le venga a la cabeza. Escriba lo que opina de sí mismo, de sus mujeres, de la guerra de Turquía, de Goethe, del proceso criminal de Fonk, del Juicio Final, de todos aquellos que tienen más autoridad que usted. Y cuando hayan pasado esos tres días usted quedará pasmado ante el reguero de novedosos y asombrosos pensamientos que han brotado de su mente. Éste es el arte de transformarse en tres días en un escritor original. (Vida y obra de Sigmund Freud. 1961, p. 222).

Sin duda, una recomendación interesante $y$, en esa época, novedosa para escribir; sin embargo, la asociación libre puede ser superflua al tratar a personas que sufren. Freud proponía a los pacientes rescatar del pozo del olvido recuerdos reprimidos siguiendo la técnica de asociar libremente, sin hipocresía y sin represiones, acerca de los distintos temas que llegan a la mente, y probablemente a la baronesa y a él les gustaba comparar la terapia con la técnica de desenterrar una ciudad (Estudios sobre la histeria. 1895). Así como los arqueólogos reconstruyen culturas antiguas a partir de reliquias y vestigios, así también los recuerdos de la mente se pueden rescatar a partir de los sueños, los síntomas y los lapsus del paciente, y con estos insumos se reconstruiría el pasado reprimido. En 1896 dio una conferencia en la Sociedad para la Psiquiatría y la Neurología ante una audiencia de profesionales de la que Krafft-Ebing -famoso psicopatólogo sexualformaba parte, y Freud sostuvo la analogía arqueológica para espanto de aquel público.

El estudioso de la histeria es como un explorador que descubre los restos de una ciudad abandonada, con paredes, columnas y placas cubiertas de inscripciones a medio borrar; puede cavar, sacarlas a la luz y limpiarlas: entonces, si tiene suerte, las piedras hablan (saxa loquuntur) (Peter Gay. Freud. Una vida de nuestro tiempo. 1990, p. 121).

Aquella audiencia escuchó escéptica y burlona cómo el psicoanálisis se presentaba como una ciencia natural, y Freud le contó a su amigo Fliess la recepción gélida del público académico y que Krafft-Ebing había dicho: "Suena como un cuento de hadas científico". La conmoción de aquellos psiquiatras y neurólogos se debía a que, con justa razón, si Freud presentaba al psicoanálisis como una ciencia, ¿cómo saber de qué "hablaban las piedras"? ¿Cómo saber cuándo una mancha de tinta tiene un significado oculto y cuándo era un simple accidente?, ¿cómo identificar si el vaso derramado sobre la mesa contiene una intensión cifrada?, en suma, ¿de qué manera plantear cuándo esos percances, descuidos y sueños son verdaderos aportes a la reconstrucción del pasado y cuándo son sólo azarosos y fortuitos? Freud creyó descubrir una ley: una señal de que la interpretación es correcta es cuando, al ser reconstruido el pasado, el paciente niega dicha reconstrucción por ser aún víctima de la represión. Pero interpretar la negación del paciente como una confirmación cobra sentido en alguna circunstancia en particular, y no constituye la regla de un método. Freud, por supuesto, conocía los problemas de comprobar de ese modo una interpretación, al punto que incluso bromeaba diciendo heads I win, tails you lose (Construcción en análisis. 1937, p. 3365), ¿por qué entonces le eran indiferentes las pautas objetivas en sus explicaciones?, ¿y por qué nunca corrigió su teoría en este punto? Tal vez le bastaba constatar pragmáticamente la verdad de su teoría, quizás el psicoanálisis es "salvaje" al basarse sobre todo en el buen juicio y prudencia del psicoanalista y paciente, como con la baronesa, pero es eso, como veremos más adelante, lo que las cartas privadas de Freud niegan.

Cuando al arqueólogo de la mente le ganaba el deseo de observar neutralmente al paciente, recurría a la idea de que la asociación libre y la atención flotante garantizaban la neutralidad de una interpretación. El filósofo Gilbert Ryle, sin embargo, argumenta que no tenemos certezas sobre la mente de otras personas ni sobre nuestra propia mente (Cfr. Gilbert Ryle. The concept of mind. 1949). En el ámbito de lo mental, no existe ningún acceso directo, incluso en la introspección comprendemos nuestra mente por 
medio de marcos interpretativos. El psicoanálisis había cuestionado la certeza de la introspección, pero parecía entronizar el oído del psicoanalista que capturaba, sin distorsiones, el mensaje esencial del paciente. Pero si ése fuese el caso, no queda claro por qué entre los psicoanalistas existen escuelas que descifran los mensajes de manera tan distinta. La baronesa hubiese creado una interpretación diferente si hubiese visitado a un psicoanalista kleiniano, greeniano, y por ello es curioso que en las asociaciones libres, los pacientes freudianos informen tener sueños freudianos, los pacientes jungianos, sueños jungianos, y así por el estilo (Malcolm Macmillan. Freud evaluated: The completed arc. 1994, p. 584). Este desacuerdo en los datos básicos de la mente sucedió también cuando Freud y Jung se separaron enérgicamente por razones de discrepancia teórica, y, sin embargo, no existió ningún hecho objetivo que permitiera elegir entre el concepto freudiano de "libido" y el jungiano de "energía". La misma falta de pruebas se siguió dando en las discusiones entre psicoanalistas posteriores, como por ejemplo, entre Melanie Klein y Anna Freud, entre Freud y Ferenczi, entre Winnicott y Bion, y entre Lacan y Green, y tan curiosa como la falta de pruebas para la disidencia es que tampoco para la complacencia exista prueba alguna.

Esas desavenencias entre lo que consideran como hechos básicos las distintas escuelas ponen en tela de juicio la perspectiva del psicoanálisis como ciencia, aunque tampoco dentro de una misma escuela existen pautas objetivas como requisito de las explicaciones científicas. Cuando Freud, por ejemplo, postuló la idea de que la mujer era una terra incógnita, un hombre hecho a medias, con una profunda envidia del pene, es muy probable que no estuviese accediendo a la mente de la baronesa, sino revelando la idiosincrasia de su horizonte cultural. Cornelius Castoriadis señala que Freud trasladó a un lenguaje pseudo-teórico los prejuicios del tendero típico de su época $(E l$ psicoanálisis, proyecto y elucidación. 1998). Freud, además de ingresar a la mentalidad de la mujer, también creyó acceder a la mente de los bebés: "Viendo a un niño que ha saciado su apetito y que se retira del pecho de la madre con las mejillas enrojecidas y una bienaventurada sonrisa, para caer en seguida en un profundo sueño, hemos de reconocer en este cuadro el modelo y la expresión de la satisfacción sexual"
(Tres ensayos sobre la teoría sexual. 1905, p. 1200). Fue la ausencia de criterios tanto en la recolección de datos como también en la elección de interpretaciones, la que hizo que el escritor Aldous Huxley escribiera comentarios sarcástico sobre el psicoanálisis.

Podríamos decir que la expresión de profunda sabiduría y de contemplación extática que a menudo vemos en [los bebés] cuando descansan plácidamente en sus cunas es la prueba manifiesta de que son grandes filósofos, absorbidos en reflexiones acerca del libre arbitrio, la predestinación y la teoría del conocimiento. ("Una superchería para nuestro siglo". Revista The Forum, 1925, pp. 313-320; luego en la revista The Adelphi, mayo de 1925).

Huxley sostiene que entre la simbología medieval y el psicoanálisis no hay rastros de evidencias ni razones para elegir entre una y otra. Si Freud no hubiese presupuesto que sólo la ciencia es portadora de conocimiento, podría haber aceptado que, en principio, distintas interpretaciones estaban en igualdad y que deliberando y sopesando se podía dialogar acerca de qué interpretaciones resultan aceptables y cuáles no. Sin embargo, Huxley también confunde las diferencias de grado entre los criterios de las ciencias naturales y las humanidades, de ahí que cuando Freud tiene afinidad con las ciencias del espíritu también lo critique: "los psicoanalistas dan la impresión de vivir en el maravilloso universo trascendental de los filósofos, donde todo el mundo tiene razón" (Aldous Huxley. "Una superchería para nuestro siglo". 1925, pp. 313-320).

Hoy, sin embargo, está en las manos de los lectores de Freud el ubicarlo en la línea continua que va desde la metodología de la explicación y los procedimientos de la comprensión. Uno de esos lectores es Huxley para quien el psicoanálisis es la superchería de nuestro siglo, otro lector es Harold Bloom, quien, a modo de halago, cree que Freud es el teólogo de nuestro tiempo: con él, entre otros creadores, valoramos nuestros pensamientos, acciones y emociones de manera distinta. Pero hoy también se ha publicado la correspondencia privada de Freud y las críticas se concentran, como en el caso de El libro negro del psicoanálisis, en la integridad ética de Freud con pacientes como la baronesa. 


\section{LA ÉTICA DE FREUD}

Peter Gay (1990), célebre biógrafo de Freud, cuestiona perspicazmente que se pretenda que la vida de Freud sea perfecta cuando sabemos que cualquier humano, por más genial que sea, tienes fallas. Si se lee las biografías de Lutero, Gandhi, Newton, Darwin, Beethoven, Keats o Kafka, nadie se aventura a ver que la obra de estos creadores es mancillada por algún aspecto de su vida, entonces ¿por qué encontrar defectos en el Freud de carne y hueso instaura pruebas contra el psicoanálisis? A pesar de esta atinada defensa, Peter Gay mantiene un presupuesto cientificista al desear que algún día el psicoanálisis alcance el camino seguro de las ciencias naturales y logré que la subjetividad del analista no interfiera al paciente. Desde las reflexiones hermenéuticas de Gadamer, como también desde las consideraciones de epistemológicas de Thomas Kuhn, las precomprensiones del humanista y los paradigmas del científico no constituyen un obstáculo, sino más bien una de las condiciones ineludibles del quehacer humano. Sin embargo, Peter Gay intenta disculpar a Freud por haberse explorado a sí mismo como testimonio y convertirse en el más informativo de sus pacientes.

Freud no consideró que sus propias experiencias fueran automáticamente válidas para toda la humanidad.Pusoapruebasusideasconfrontándolas con las experiencias de sus pacientes [...]. Sus casos más famosos reflejan con elocuencia su compromiso simultáneo con la individualidad y la generalidad; cada caso describe un paciente irrepetible que al mismo tiempo pertenece a una cierta categoría. (Freud. Una vida de nuestro tiempo. 1990, p. 118).

Desde la perspectiva de El libro negro del psicoanálisis y de Michel Onfray (Le crépuscule d'une idole. L'affabulation freudienne. 2010), sin embargo, la defensa de Peter Gay cubre, erradamente, partes que no son atacadas, pues ahí se sostiene que el psicoanálisis, lejos de ser una disciplina científica, es el sueño elaborado de Freud, un mito sin respaldo de casos significativos cuantitativamente $y$, en suma, una autobiografía que quiere pasar por ciencia mediante los casos clínicos tergiversados por el autor de Estudios sobre la histeria. Habrá que conocer cuáles son las nuevas críticas a Freud en este punto.
Freud fue un ser intenso, un neurótico que podía escribirle a Martha, aún de novios, exigencias pasionales y tragicómicas: "Ahora tengo que hacerte una pregunta de trágica seriedad. Contéstame por tu honor y tu conciencia si el último jueves a las once sentiste menos cariño hacia mí, o más fastidio que de costumbre, o acaso me fuiste realmente 'infiel', como dice la canción" (Ernest Jones. Vida y obra de Sigmund Freud. 2003, p.112). Estaba preso por unos celos que sólo existían en esa caldera que era su amor pasional. "Cuando vuelven a mi recuerdo tu carta a Fritz [-le escribe a Martha-], pierdo todo control sobre mí mismo, y si tuviera el poder necesario para destruir todo el mundo, inclusive nosotros dos, [...] lo hacía sin vacilar" (Jones, op. cit. p. 118). Cuando Martha guardaba silencio, Freud la consideraba evasiva, y le decía que prefería que las cosas se plantearan como un conflicto a la luz del sol.

Desde las manifestaciones más groseras a las más sutiles, Ernest Jones sostiene que nada revela de manera más penetrante cuál es la esencia de una persona que sus actitudes hacia el sentimiento fundamental de la vida que es el amor. Con una gran pasión, Freud le escribió a Martha más de novecientas cartas durante cuatro años, tiempo en el que vivieron separados. Ambos acostumbraban a escribirse a diario y las cartas de cuatro páginas se consideraban cortas -algunas llegaron a veintidós-, y al emprender la correspondencia Freud le consultó a Martha si prefería la escritura latina o gótica. Muy enamorados, Freud la quería, además, como camarada de lucha intelectual y, craso error, intentó que se le uniera y atacara a la familia de ella, y, al no enfrentarse a los padres, Freud la acusaba cruelmente de debilidad y cobardía, y decide escribirle un ultimátum: si no admite las críticas justificadas de él, ella lo traiciona.

En ese caso pondremos fin a nuestra correspondencia. Ya no tendré ninguna exigencia que hacer. Mi anhelante y tempestuoso corazón habrá muerto. [...] Si no eres aquella por quien te he tomado, mía es la culpa por haber buscado tu amor sin conocerte [...] Una mujer debe suavizar, no debilitar al hombre. (Jones, op. cit., p. 126).

Al día siguiente, bajo un intenso conflicto pasional, él se disculpa. "Todas estas manifestaciones de él - 
informa Jones- provienen del primer mes de noviazgo" (Jones. op. cit., p. 125). Freud le había exigido a ella absoluta identificación con él, pero llegó el momento en el que se percató del error de poseer una muñeca.

Renuncio a mi exigencia. No necesito un compañero de armas, tal como yo tenía la esperanza de hacer de ti: soy bastante fuerte para luchar solo. No volverás a oír de mí ni una sola palabra áspera. Observo que no logro en ti lo que he querido, y que perderé a mi amada si persisto. He reclamado de ti lo que no está en tu naturaleza, y nada te he ofrecido a cambio de eso... [...] Tú sigues siendo para mí mi preciosa y dulce amada (Jones. op. cit., p. 125).

Freud fue tiránico con Martha, le prohibió permanecer en la casa de una amiga de años de quien Martha le contó eufemísticamente que esa amiga 'se había casado antes de la boda', y Freud -iracundo profeta bíblico- le prohibió rigurosamente "el contacto con semejante fuente de contaminación moral" (Jones. op. cit., p. 127). Continuaron otros enfrentamientos y siendo válidas distintas interpretaciones una de ellas ve el enamoramiento de Freud como muestra de un carácter pasional y neurótico. A Freud, que le encantaba el conflicto, una vez casado se le reveló la figura de la suegra, una devota ortodoxa y ritualista de estrictas reglas, precisamente lo que Freud despreciaba. Y, en una de las cartas, trazó un bosquejo agudísimo -digno de la pluma de Kafka- acerca de la madre de su novia:

Es fascinante, pero extraña, diferente, como lo será siempre para mí. Busco en ella las semejanzas contigo, pero difícilmente encuentro alguna. Su misma calurosa cordialidad tiene el aspecto de condescendencia, y es una persona que exige ser admirada. Preveo que tendré más de una oportunidad de hacerme antipático a ella, y no me propongo evitarlo (Jones. op. cit., p. 119).

Incluso, en otra oportunidad, Freud cita una frase de Meynert según la cual la primera condición en todo matrimonio es el derecho de echar a los parientes políticos. Por otra parte, acerca de su relación con los pacientes, es ingenuo concluir, a partir de dos fuentes, que Freud despreciaba a sus pacientes. Por ejemplo, dice Ludwing Binswangeren Mis recuerdos de Sigmund Freud: "otra ves le pregunté en qué términos estaba con sus pacientes. Respuesta: 'les retorcería bien el cuello a todos"”; y Sándor Ferenczi en su Diario clínico cuenta que Freud le dijo: "Los pacientes son una chusma. Sólo son buenos para permitir que nos ganemos la vida, y como material para aprender. De todas maneras, no podemos ayudarlos". Estas circunstancias de la vida de Freud son inocuas y muestran a un Freud más conflictivo y pesimista algunos días, y sólo una visión archiangelical pretende encender velas a la imagen de un Freud siempre amable, compresivo y mesiánico; y en varios momentos El libro negro exige de Freud esa imagen bonachona y de bonhomía. De ahí que hayan críticas superfluas que denuncian toda la correspondencia privada de Freud, incluso aquellas humoristas como la carta privada que Freud le escribió a su amigo Wilhelm Fliess antes de 1900: "En tres semanas será necesario inquietarse por saber si los negros llegarán a tiempo para calmar el apetito del león" (Mikkel Borch-Jacobsen y Jean Cottraux. Le Livre noir de la psychanalyse. 2005, p. 91). Ernest Jones sostuvo que el temperamento intenso del genio de Freud fue el resultado de combinar, por un lado, poderosas fuerzas instintivas, y, de otro lado, poderosas represiones. Así, Freud podía tener consideraciones feroces sobre sus pacientes, pero también podía sostenerlos.

Resulta interesante que a sus ochenta años, con los ojos aún penetrantes, aunque con el gesto de un observador desencantado, se enteró de que su ex amigo Fliess había muerto y que las cartas entre ambos ahora se hallaban en el estante de un librero de Berlín. La princesa Marie Bonaparte les había echado un vistazo y confirmó la autoría de las cartas: "Después de todo -le dijo a Freud-, ; conozco su letra!" ${ }^{4}$, y Freud quedó aterrado. La princesa compró las cartas y, en lugar de entregarlas a la familia Freud, que seguro las desaparecerían, prometió depositarlas en una biblioteca

4. Marie Bonaparte a Freud, 30 de diciembre de 1936. Citada en la introducción a Freud-Fliess, xviii-xix. Freud-Fliess. Briefe an Wilhelm Frliess 1887-1904, comp. de Jeffrey Moussaieff Masson, con la colaboración de Michael Schröter y Gerhard Fichtner, 1986. Versión inglesa, The Complete Letters of Sigmund Freud to Wilhem Fliess, 1887-1904, comp. y traducción de Jefferey Moussaieff Masson, 1985. 
con la condición de que nadie las viera hasta cien años después de la muerte de Freud.

Anciano y achacado por un cáncer a la boca y por las terribles vivencias de las guerras, Freud se refería a su mundo con una metáfora gris: su vida era como a "una pequeña isla de dolor en un mar de indiferencia" (Ernest Jones. Vida y obra de Sigmund Freud. 2003, p. 16), y, así desanimado, renegaba de los logros de la situación psicoanalítica. Antes, optimista, había escrito:

[La intención del psicoanálisis es] fortalecer al yo, hacerlo más independiente del superyó, ampliar su campo de percepción y expandir su organización de modo que pueda apropiarse de nuevas partes del ello. Donde había ello, debe haber yo. Es un trabajo cultural parecido al drenaje del Zuyder Zee (Nuevas conferencias de introducción al psicoanálisis.1933, p. 824).

Pero ahora, en 1937, Freud en Análisis terminable e interminable se mostraba escéptico sobre la cura, más cauteloso, menos triunfalista y, en el mejor de los casos, decía, las ganancias del yo en el tratamiento serían temporales. ¿Tendría algo que ver en este declive de las expectativas del psicoanálisis enterarse que circulaban por ahí las cartas a Fliess? ¿O era el clima repugnante del régimen nazi en el que los torturadores aullaban de goce al obligar a judíos -niños, mujeres y ancianos- a practicar el saludo hitleriano y luego asesinarlos? ¿Sería la proximidad con la muerte, por la vejez, que podía llevarlo a admitir, esta vez con un nuevo matiz, las palabras: "debes a la Naturaleza una muerte"? (Ernest Jones. Vida y obra de Sigmund Freud. 2003, p. 42).

Acababa de sufrir, además de varias muertes de amigos y familiares, la muerte de su mascota Jo-Fi, una chow de la que admiraba la simplicidad de su vida, libre de los conflictos de la civilización, en suma, una existencia completa. Y, como confidencia, le contó a
Marie Bonaparte, que mientras acariciaba a Jo-Fi se había sorprendido entontando una melodía que podía ser el aria de Don Giovanni: 'Un lazo de amistad nos une' (Jones, op. cit. p. 656).

En 1939 sufría dolores por la prótesis bucal y el tejido canceroso de la mandíbula, ulcerado, desprendía un olor desagradable que su nueva mascota detectaba y huía en un rincón lejos de él. Nada lo derrumbaba, ni los críticos ni las amenazas ni las dudas, pero la distancia de la perrita destruyó a Freud, había llegado el final. En una frase digna del existencialismo, Freud había escrito años antes que el proverbio 'si quieres preservar la paz, ármate para la guerra' debía ser parafrasearlo: 'si quieres sobrellevar la vida, prepárate para la muerte'. (Consideraciones de actualidad sobre la guerra y la paz. 1915, p. 1016).

Acercarse a la vida de Freud no debería proponer un ataque ad hominem, sino más bien la ocasión de preguntar por la coherencia o no entre lo escrito en los ensayos y en las cartas, pues si bien el psicoanálisis, en la perspectiva hermenéutico-relacional, ha sabido enfrentar las anteriores críticas epistémicas y terapéuticas, ahora con El libro negro la fidelidad de los casos emblemáticos estarían en discusión. Lo que los investigadores señalan es que mientras Freud en los ensayos notificaba al público los éxitos terapéuticos de su método, en su epistolario privado, en cambio, describía los retrocesos en las sanaciones de sus pacientes. De ser esta información correcta, el personaje de nuestra mitología y teología contemporánea se ve modificado y con él su terapéutica. Es cierto que existen críticas menores, como que en algunas tardes Freud se quedaba dormido mientras atendía a los pacientes ${ }^{5}$, cobrando 415 euros por sesión, pero lo relevante es la denuncia de que Freud habría falsificado algunos resultados de los pacientes con los que trabajó.

Una primera controversia se observa en el caso de Dora, quien, años después de pasar por la psicología profunda, continuaba padeciendo vértigos y trastornos

5. Carta de Freud a Fliess del 15 de marzo de 1898: "Duermo durante los análisis de la tarde". "Algunos pacientes lo atestiguarán. Por ejemplo, Helene Deutsh, futura psicoanalista, revelará que aquél se adormeció al menos en dos oportunidades durante su análisis. ¿Es grave que el psicoanalista duerma mientras lleva adelante un análisis, cuando se le paga por escuchar lo que se le dice? No, responde Freud. Y construye una teoría que [...] justifica sus debilidades existenciales: el analista puede dormir porque se sirve "de ello su inconsciente como instrumento', escribe en Consejos al médico sobre el tratamiento psicoanalítico. Michel Onfray. Freud. El crepúsculo de un ídolo. Traducción de Horacio Pons. México D.F.: Santillana, 2011, p. 314. 
digestivos (Michel Onfray. Freud. El crepúsculo de un ídolo. 2011, p. 339). Cuando por primera vez tocó la puerta de Freud y se echó en el diván y narró su historia, Freud procedió como un detective impetuoso que debía correr, con fuerza, las cortinas y las alfombras de los decorosos salones sociales, y no fue empático con ella. No observó la necesidad que tenía esta adolescente de contar con un guía confiable en un mundo adulto cruelmente egoísta, y fue en el estudio sobre Dora que Freud sostuvo que, en varias situaciones, cuando los pacientes enfatizan una negación del tipo " $i$ no!, yo no deseo a mi madre!", es probable que la verdad se encuentre al borrar la partícula negativa. " No' en tales casos, significa "sí'” (Freud. Análisis fragmentario de una histeria. 1905, p. 513). Años después, aún sin concebir los peligros del micropoder de tal concepción, Freud citó el dicho inglés comentado líneas arriba: heads I win, tails you lose (Construcción en análisis. 1937, p. 3365). Dictatorial o sofista en este aspecto, Freud cometió el error técnico -circunstancia reconocida incluso por Peter Gay (Freud. Una vida de nuestro tiempo. 1990, p. 289)- de presionar a Dora para que aceptara una interpretación con contenido sexual. La adolescente, dolida, comentó: "sabía que usted diría eso" y Freud respondió: "es decir, usted lo sabía". La teoría psicoanalítica que, de acuerdo con sus críticos, se blinda de cualquier crítica ¿también resulta irrefutable en el consultorio con el paciente? ¿Acaso -siguiendo una metáfora del gusto de Freuden un quirófano el paciente tiene derecho de indicar al médico dónde debe dirigir el bisturí? De ninguna manera.

El segundo caso es el de Elisabeth von $\mathrm{R}$-la misma paciente con quien había hecho la analogía del psicoanálisis como arqueología-, que sufría de problemas al caminar y a quien Freud había señalado que reprimía dos deseos pecaminosos, amaba a su cuñado y anhelaba la muerte de la hermana. Al enterarse que ella iría a un baile privado, Freud escribió haberla visto recuperada, incluso bailando; tiempo después, Elizabeth von R, sin embargo, negó que Freud hubiera resuelto sus síntomas neuróticos y recordaba que él trataba de convencerla del deseo erótico por el cuñado y del deseo fraticida. ¿Elizabeth von $\mathrm{R}$, ahora por vergüenza, negaba la interpretación de Freud? Es probable.
Anna $\mathrm{O}$ constituye el tercer caso problemático, a pesar de que para Freud constituyó una cura célebre. El historiador Henri Ellenberger, al investigar los archivos del sanatorio en el que Anna O había sido tratada, leyó el informe escrito por Breuer -quien había atendido a Ana $\mathrm{O}$ junto con Freud- en el que declaraba que la paciente, después del tratamiento de la talking cure -la cura por la palabra publicada por Freud-, continuaba con los mismos síntomas histéricos. En su correspondencia privada, es más, el propio Freud señaló que la paciente seguía sufriendo alucinaciones y otros trastornos, mientras que en los ensayos afirmaba que la talking cure era un triunfo terapéutico. En sus cartas Freud reconocía que Anna O seguía enferma, pero en sus escritos públicos afirmaba lo contrario. ¿El estado anímico de Ana $\mathrm{O}$ era demasiado ambivalente? ¿Breuer tuvo un lapsus al escribir la epicrisis sobre Ana O? ¿Sucederá, cómo alega André Green, que el caso de Anna O representa una cura en diferido (André Green. "Mithes et mystifications psychanalytiques", Le Monde, 28 de diciembre de 1995)? Es posible.

Además de Anna $\mathrm{O}$ un cuarto caso conocido es el tratamiento al Hombre de las Ratas, un hombre obsesivo que, gracias a sus contradicciones y su lógica perversa, interesó a Freud. Los obsesivos -generalizóson racionalistas y supersticiosos, son acosados por dudas enloquecedoras y, a diferencia de los histéricos, tienen ingeniosas triquiñuelas al elaborar resistencias al psicoanálisis. En el caso del Hombre de las Ratas, Freud concluyó públicamente que el paciente había sido restablecido y sus síntomas eliminados, pero a Carl Jung, en privado y unas semanas después, le confesó que el Hombres de las Ratas no había solucionado en modo alguno sus problemas. Esto es ininteligible.

Presentado también como gloria terapéutica es el caso de El Hombre de los Lobos, y en éste, sostienen los críticos, habría evidencias rasgos de imprecisiones. Para sopesar este caso, tengamos presente las palabras que, una vez concluida la primera sesión, le confesó a Freud. "Me confesó las siguientes transferencias: estafador judío, le gustaría darme por detrás y cagarse en mi cabeza" (Correspondencia Freud-Ferenczi, 1990, p. 328.). Transcurridas varias sesiones, el paciente le cuenta sueños y Freud le explica que en el sueño muchas veces los deseos se transforman en horrores. Así, conjeturó Freud, el paciente, en el pasado, debió 
de sorprender a los padres en pleno acto sexual al año y medio de nacido, y esto le habría provocado una inclinación homosexual pasiva. Lo supo Freud gracias al método psicoanalítico por el cual, a partir de que el paciente soñó con lobos blancos, pudo determinar que esos animales simbolizaban la ropa interior de los padres, y también pudo reconstruir la escena reprimida del paciente, origen de todos sus problemas. En dicha escena presenciada y luego olvidada por el paciente a la edad de un año y medio, había visto a los padres manteniendo relaciones sexuales, y nada menos que el coito a tergo y realizado, cabalísticamente, tres veces.

Que aquel paciente, en su momento, haya tolerado tales interpretaciones da una idea de su grave situación, pero lo significativo es que Freud lo presentó como un caso resuelto. Sesenta años después, no obstante, la periodista Karin Obholzer siguió el rastro del Hombre de los Lobos hasta Viena, y concertaron una entrevista. De dicha reunión nos enteramos que el paciente había considerado absurda la interpretación y la reconstrucción que hizo Freud de su caso y, pese a lo que decía Freud en sus publicaciones, nunca se sintió curado. Ese hombre, a sus noventa años, negaba el mito de su curación y contaba que, una vez fallecido Freud, fueron algunos discípulos quienes no lo dejaban en paz ofreciéndole psicoanálisis gratuito. (The WolfMan Sixty Years Later. 1982). El propio Hombre Lobo rechazaba el mito de su curación:

La teoría -le dice a Obholzer- que Freud me había curado ciento por ciento [...] y es por esa razón que Gardiner me alentó a escribir mis memorias para mostrarle al mundo entero cómo Freud había curado a una persona muy golpeada". (Muriel Gardiner. The Wolf Man: By the Wolf Man. 1971).

Una historia como ésta parece inverosímil y la pregunta que como un flechazo se cruza en la mente del lector es si el Hombre de los Lobos, a causa de su inestabilidad emocional, le hizo creer a Freud que se había curado y, ahora, cambiaba de versión. De acuerdo; es posible y el paciente pudo haber fabulado todo: a Freud le pudo decir que sí se sentía curado y hoy negarlo. Pero de ser así, ¿cómo explicar que, como demostró la investigación de la periodista, fuese el director de los Archivos Freud, Kurt Eissler, quien le enviaba al Hombre de los Lobos periódicamente dinero con tal de que permaneciera en el anonimato? Este es precisamente el tema sobre la ética, ya no sólo de Freud, sino también de las escuelas psicoanalíticas, cuyas estructuras verticales las acercan peligrosamente a las sociedades secretas y cónclaves papales. Si tales escuelas no desean ser consideradas como sectas, deberían pronunciarse sobre por qué Freud, en los textos psicoanalíticos, presentaba a algunos pacientes como muestras de logro terapéutico, cuando, acerca de esos mismos pacientes, en su correspondencia privada decía lo contrario. El libro negro del psicoanálisis fue publicado en Francia en el 2005 y el revelador descubrimiento de la periodista Karin Obholzer fue divulgado en 1982.

\section{REFERENCIAS}

Aristóteles (1985). Ética Nicomáquea. Ética Eudemia. Traducción de Julio Pallí Bonet. Madrid: Gredos.

Assoun, Paul-Laurent (1982). Freud. La filosofía y los filósofos. Traducción de Alberto Luís Bixio. Buenos Aires: Paidós.

Borch-Jacobsen, Mikkerl; Jean Cottraux; Didier Pleux y Jacques Van Rillaer (2007). Le Livre noir de la psychanalyse. Vivre, penser et aller miéux sans Freud. Paris: Les Arènes, 2005. Versión en castellano El Libro Negro del Psicoanálisis. Vivir, pensar y estar mejor sin Freud. Traducción de Sergio Javier Di Nucci. Buenos Aires: Sudamericana.

Castoriadis, Cornelius (1998). El psicoanálisis, proyecto y elucidación. Traducción de Horacio Pons. Buenos Aires: Nueva Visión.

Chalmers, Alan (2005). ¿Qué es esa cosa llamada ciencia? Traducción de José Padilla Villante. Decimoséptima reimpresión, Madrid: Siglo XXI editores.

Coderch, Joan (1995). La interpretación en psicoanálisis. Barcelona: Herder.

Davidson, Donald (1982). "Paradoxes of irrationality", en: R. Wollheim y J. Hopkins (comps.), Philosophical Essays on Freud, Nueva York/ Cambridge: Cambridge University Press. 
Eysenck, Hans. Decadencia y caída del imperio freudiano. Buenos Aires: editorial virtual http:// www.laeditorialvirtual.com.ar/pages/Eysenck/ EysenckFreud_01.htm. 2005. [1985]

Freud, Sigmund. Obras completas. Traducción de Luis López-Ballesteros y de Torres. Madrid: Editorial Biblioteca Nueva, 1948. VOL. III

1895 "Estudios sobre la histeria", 1900 "La interpretación de los sueños" 1905 "Tres ensayos sobre la teoría sexual" 1905 "Análisis fragmentario de una histeria" 1908 "La moral sexual y la nerviosidad moderna"

1910 "El psicoanálisis silvestre"

1913 "Sobre la iniciación del tratamiento"

1914. "Puntualizaciones sobre el amor de transferencia"

1915 "Consideraciones de actualidad sobre la guerra y la paz"

1917 "Duelo y melancolía"

1930 "El malestar en la cultura"

1933 "Nuevas conferencias de introducción al psicoanálisis"

1937 "Construcciones en psicoanálisis"

Fromm, Erich (1970). The Crisis of Psychoanalysis. Nueva York: Holt, Rinehart and Winston Inc.

Gardiner, Muriel (1971). The Wolf Man: By the Wolf Man. Nueva York: Basic Books.

Gay, Peter (1990). Freud. Una vida de nuestro tiempo. Traducción de Jorge Pisatigorsky. Barcelona: Paidos

Green, André (1995). "Mithes et mystifications psychanalytiques", Le Monde, 28 de diciembre.

Grünbaum, Adolf (1984). The foundations of psychoanalysis: A philosophical categories. Chicago: University of California Press.

Jones, Ernest (1961). Vida y obra de Sigmund Freud. Traducción de Marco Carlisky y José Cano Tembleque. Barcelona: Anagrama.
Kuhn, Thomas (1962). The Structure of Scientific Revolutions. Chicago, University of Chicago Press.

Lacan, Jaques. Seminario 5. Las formaciones del inconsciente. http://planetafreud.files.wordpress. com/2011/05/sem05_las_formaciones_del_ inconciente.pdf

Macmillan, Malcolm (1994). Freud evaluated: The completed arc. Cambridge, MA: The MIT Press.

Masson, Jeffrey Moussaieff (comp.) con la colaboración de Michael Schröter y Gerhard Fichtner (1985). Freud-Fliess. Briefe an Wilhelm Frliess 1887-1904. Versión inglesa, The Complete Letters of Sigmund Freud to Wilhem Fliess, 18871904, comp. y traducción de Jefferey Moussaieff Masson

Obholzer, Karin (1982). The Wolf-Man Sixty Years Later. Londres: Rouledge y P. Kegan

Onfray, Michel (1996). El vientre de los filósofos. Crítica de la razón dietética. Traducción de Rosa de Diego. Madrid: Oria.

Onfray, Michel (2010). Le crépuscule d'une idole. L'affabulation freudienne. París: Éditions Grasset $\&$ Fasquelle. La versión en español es Freud. El crepúsculo de un ídolo. Traducción de Horacio Pons. México D.F.: Santillana, 2011,

Popper, Karl. Conjectures and Refutations. The Growth of Scientific Knowledge, London: Routledge \& Kegan Paùl, 1974 [1961].

Rorty, Richard (1993). Ensayos sobre Heidegger $y$ otros pensadores contemporáneos. Escritos filosóficos 2. Traducción de Jorge Vigil Rubio. Barcelona: Paidós.

Ryle, Gilbert (1949). The concept of mind. Chicago: University of Chicago Press.

Wordsworth, William. William Wordsworth. Edición y traducción de Bel Atreides. Barcelona: DVD e 